\title{
PERCEPÇÃO INSENSÍVEL: HIPÓTESES SOBRE O INCONSCIENTE DAS IMAGENS
}

\author{
INSENSITIVE PERCEPTION: \\ HYPOTHESES ON THE UNCONSCIOUS PICTURES
}

\author{
Priscila Rossinetti Rufinoni
}

Professora do Departamento de Filosofia da Universidade de Brasília - UnB.

\begin{abstract}
RESUMO
Este ensaio busca pensar as relações entre percepção, natureza e representação a partir, primeiramente, dos Ensaios de Locke. Neste texto de Locke, será enfatizada a noção de atenção do sujeito à coisa pensada/representada. Por fim, como tentativa de escapar a esta perspectiva subjetiva em construção já nos século XVII, a percepção como entendida por Locke será confrontada à noção de percepção insensível de Leibniz. Espécie de oximoro, a percepção insensível repõe, nos termos modernos, a possibilidade de uma intersubjetividade, ou de uma objetividade anterior e externa ao sujeito, retomada por Walter Benjamin para pensar a modernidade.

Palavras-chave: Percepção; Percepção insensível; Locke; Leibniz.
\end{abstract}

\begin{abstract}
This essay aims presentation the relationship between perception, nature and representation in the Locke's Essay. In the Essay, this text show the subject's attention to the thing represented and thought. In second part, the Locke's notion will be confronted with the perception insensible of Leibniz. This perception insensible aims presentation Leibniz's intention to think an intersubjective perspective.

Keywords: Perception; Perception insensible; Locke; Leibniz.
\end{abstract}

E, como uma mesma vila vista de diferentes pontos parece toda outra, e é como que multiplicada perspectivamente, o mesmo ocorre com a multiplicidade infinita de substâncias simples, nas quais parece haver como outros tantos universos diferentes, mas que não são senão as perspectivas de um só a partir dos diferentes pontos de vista da cada Mônada (LEIBNIZ, Monadologia, § 57)

\section{Da percepção da natureza à natureza da percepção}

No centro da mesa, da xícara de chá irradia-se o foco, em círculos concêntricos. A moça, a sala, a cadeira, tudo em torno obedece a esse movimento centrípeto da atenção, em cujas bordas desvanecem não só a nitidez visual, mas também a impressão táctil. 0 fundo atrás da cadeira e da dama, de um verde acinzentado, não obedece à perspectiva, não é espacialmente concebido, não é, também, qualquer coisa de palpável - a continuidade da

${ }^{1}$ A comparação com Piero dela Francesca ainda é de Baxandall. parede? Uma sombra? Um outro cômodo entrevisto? - não possui nem uma espacialidade, nem uma substancialidade. A representação nesse extremo do quadro não representada nada, senão a própria desatenção que impossibilita que algo seja representado. Fixa-se um limite: o movimento do olhar esbarra no espaldar da cadeira, mal o vê, daí sua perspectiva achatada, dissolve-se no fundo e é devolvido para o centro, a xícara de chá. Descrevo, para iniciar o debate, a pintura de Jean-BaptisteSimeón Chardin, Dama tomando chá, de 1735, da qual se vale Michael Baxandall para compreender os movimentos que levaram às profundas mudanças na maneira de se entender tanto os mecanismos ópticos, quanto a representação do mundo a eles adequada. 0 mundo de Chardin não possui, em si mesmo, substância, como, talvez, possuía o mundo representado por Piero della Francesca, em que têm a mesma tactibilidade, a mesma nitidez tocada pelo olhar, todas as partes, do primeiro plano aos planos infinitos, engolidos na atmosfera'. Tudo pode ser apreendido nessa grade representativa, tudo se nos é apresentado como coisa, como ente, como 
há, entre esse ocaso do mundo e o olhar que o capta, uma cópula que desvela a verdade do visível até em suas dobras. Não se pode dizer o mesmo dos borrões difusos que arrematam a borda dos círculos de atenção no quadro de Chardin.

Quando outro teórico da representação, Roger de Piles, em seu Curso de pintura por princípios, de 1708, precisa dar conta de pensar a relação entre o aparelho óptico e o que lhe é externo, o claro escuro é o recurso para unificar, na pintura, o que chega ao olho como descontínuo. Se a natureza ainda é una em De Piles, a unidade representada já não o é, ela depende da "relação com o espaço que o olho pode razoavelmente abarcar sem ser distraído por inúmeros objetos separados". As massas de claro e escuro "em mútua ajuda", permitem ao pintor "fazer brilhar em seu quadro seus claros e suster por massas escuras os olhos, para não deixá-los entretidos com objetos menos sensíveis" (DE PILES, 1989, pp.182-185). De alguma forma, se a natureza possui unidade, esta é aberta pela atenção do olho, ele deve entreter-se, centralizar seu foco. Trazer à luz ou mergulhar nas sombras são artifícios para conduzir o olhar, pois este já não tem como percorrer a luminosidade completa de uma cena de Piero della Francesca, ou mesmo dos penhascos azulados de Leonardo, mestre do sfumato, mas não do claro-escuro teatral ${ }^{4}$. O desenvolvimento da óptica explicita essa nova forma de compreensão do ato de ver, e um estudioso citado por Baxandall, o holandês Pieter Camper, em 1746, se refere claramente a uma relação atomizada da retina à coisa focada:

${ }^{4}$ A questão em Leonardo é amainar a dureza dos contornos, acentuando o relevo, mas não dar unidade às partes descontínuas, como podemos ler no trecho: "Um objeto pintado em branco e preto parecerá mais afortunado que nenhum outro. Mas recorda pintor, que vistas tuas figuras das cores mais claras que puder, porque se as pinta de cores escuras serão de pouco relevo e evidência desde longe". Tratado da Pintura. Madri: Editora Nacional, 1982, p. 253.

${ }^{5}$ Tanto Erwin McCann quanto Luciana Zaterka sublinham a herança de Robert Boyle, cientista da teoria corpuscular, neste ponto. In: ZATERKA, Luciana. "Robert Boyle e Jonh Locke: hipótese corpuscular e filosofia experimental" in Circumscribere, 1 (2006), pp. 58-66; McCANN, Erwin, "Lockean Mechanism" in Locke, ed. V. Chappell Oxford: Oxford University Press, 1998.

${ }^{6}$ Esses poderes seriam a causalidade do corpo, compreendidos a partir da teoria corpuscular: "partículas imperceptivelmente pequenas que induzem movimento nos nosso órgãos dos sentidos, nervos e, por fim, cérebro". McCANN, op cit.

${ }^{7 " A}$ doutrina escolástico/aristotélica das qualidades postulava que muitas das qualidades sensíveis dos objetos são qualidades reais, ou seja, são entidades reais que existem ou inerem os objetos, e que a percepção deles envolve a mente aceitando a forma dessas qualidades tal qual elas existem nos objetos". McCANN, Erwin, op cit.
A retina [...] não tem a mesma sensibilidade em todas as suas partes [...] A parte mais sensível é a que fica perto do ponto de junção do nervo óptico, isto é, no lugar oposto ao eixo visual. Corolário: [...] isso mostra claramente por que, nos quadros, somente uma parte deve ser iluminada e pintada com maior nitidez possível (Apud BAXANDALL, 2006, p. 143)

Houve, como escreve Baxandall em relação à teoria da arte, uma mudança não apenas do estatuto da visão, agora objeto de estudos da óptica, mas também da própria concepção da exterioridade que se dá a ver. Para se conceber a representação daquilo que era a "natureza" em si mesma, o século XVIII precisa da precedência do olho, e, em última instância, do sujeito. Para o estudo que citamos, interessa mais a recepção da filosofia no que ela incide na reorientação das formas de ver, e é neste sentido que o autor aponta para o que seria uma vulgarização da teoria do conhecimento do inglês John Locke, cujos textos sobre o entendimento humano foram publicados em 1690:

[...] naqueles anos, as ideias de Locke sobre a percepção humana estavam bem difundidas por toda a Europa ocidental. Uma resposta lockiana diria que a afirmação de Camper só poderia ser razoável se as pessoas vissem um quadro não como uma representação da substância - ou da Natureza, como se dizia no Renascimento -, mas como a representação de um ato de percepção da substância (BAXANDALL, 2006, p. 144)

Para Baxandall, não interessa, ou ao menos não é central, a polêmica em torno da substancialidade nos Ensaios de Locke. Sabemos que há objeções sobre o que entenderia Locke por substrato, substância, esse "não sei que" cujo conhecimento se daria por seus "acidentes", seus poderes, como escreve Locke: cor, cheiro, som. Substracto que teria, entretanto, realidade em si mesmo nas qualidades que lhe são inerentes, não apreensíveis pela sensação, como solidez, extensão (a dimensão espacial), figura, movimento e repouso (mobilidade), número, tamanho, situação, textura e movimento das partes $^{5}$. O problema seria qual o estatuto das tais qualidades primárias, seriam elas ontologicamente ligadas à matéria, embora insensíveis, enquanto as secundárias, os "poderes" enviados da matéria aos órgãos dos sentidos, seriam apenas percebidos por meio das coisas, sem a elas inerir6? Mas, não se voltaria, então, ao mesmo patamar aristotélico escolástico que difere qualidades essenciais de acidentes ${ }^{7}$ ? E como entender que todo conhecimento advém "numa palavra, da experiência", na fórmula célebre de Locke, se a experiência mesma é insuficiente para conhecer o que o próprio intelecto explicita como inerente às coisas? Ou estaríamos distantes do aristotelismo, pois a teoria corpuscular de Boyle teria indicado a Locke qualidades próprias à matéria em seu estatuto atomístico, embora não apreensíveis pela sensação, sem, entretanto, pressupor-se daí uma 'matéria incognoscível', mas sim 
uma matéria cujas qualidades reais devem ser experienciadas a partir de seus "poderes" secundários, até descobertas científicas que deslindariam o átomo das coisas? Nas palavras claras de Locke:

Portanto seja qual for a natureza secreta e abstrata da sustância em geral, todas as nossas idéias das espécies particulares e distintas da substância nada são exceto várias combinações de idéias simples, coexistindo numa, embora desconhecida, causa de sua união, fazendo com que o todo subsista por si mesmo (LOCKE, 1988, p. 76)

Entendo, com autores como Luciana Zaterka, que Locke é mais aproximado de um cientista experimental que de um confuso continuador da lógica escolásticoaristotélica, apesar da terminologia em suma aristotélica. Locke pode ser visto como cientista experimental e seu livro como coerente, mesmo sem esquecer as passagens problemáticas e contraditórias, notadamente esse capítulo VIII do Livro II sobre qualidades primárias e a ironia quanto à ideia, mitológica e infantil, de um substrato final, o elefante que sustenta o mundo sobre uma tartaruga, apoiada em "não sei o quê"8. O "seja qual for" faz alusão àquele pressuposto já enunciado na Introdução aos Ensaios de não dar conta nem mesmo da mente em sua característica física e em sua essência. Se nem mesmo o aparato do conhecimento como foco de si mesmo, centro do livro, terá visada essencialista, o 'seja qual for' pressupõe não só um limite "cético" delimitação de interesse e de escopo. Se há tal coisa que seja a "substância", se há uma mente do ponto de vista físico ou essencial, não é em um estudo do 'conhecimento' que vamos enfrentar tais perguntas. Não apenas como aspecto formal do texto, mas mesmo como questão epistemológica intrínseca ao objeto tratado, Locke é claro ao delimitar o que pode ou não pode ser conhecido. A própria incognoscibilidade é tematizada, à maneira da desatenção que se dissimula nas bordas da tela de Chardin $^{10}$.

Ademais as contradições internas ao texto dos Ensaios, escrito ao longo de 20 anos, não precisam ser vistas como anátemas, mas como movimentos e oscilações legítimos de um pensar que se questiona e se experiência em sua própria exposição. Ou seja, ciência no momento mesmo em que se expõe como ciência, ao pensar com os instrumentos tradicionais e pôr-se diante das novas determinações de uma teoria corpuscular ou de um mecanicismo cartesiano. Não procuramos aqui, como também não procurava Baxandall, decidir sobre as controvérsias internas do cientificismo do século XVII. Se há um 'resultado', uma solução, interessam-nos menos que seu processo. De qualquer perspectiva que tomemos a polêmica, entretanto, a "natureza" já deve ser "submetida a tormentos (vexaciones)" para que se desvele em sua substancialidade, seja esta ontológica ou material. $\mathrm{O}$ próprio posicionamento de tal polêmica sugestiona um limite, um esgarçamento.

Do ponto de vista da teoria da sensibilidade, há duas questões que podem ser sublinhadas a partir dos exemplos, uma delas diz respeito ao estatuto da exterioridade e da percepção evidentemente, e outra ao estatuto da própria verdade. Para Oswaldo Porchat, - laço que dava substancialidade à natureza do Renascimento sobrevive até o empirismo cético de David Hume, crítico de Locke, e a virada epistemológica de Immanuel Kant, já no século XVIII; este laço se caracterizava por uma realidade por si mesma e por uma verdade das coisas à disposição da cognição humana, mas independente dela:

O realismo metafísico postula uma realidade concebida como existente em si mesma, como uma natureza constituída de modo determinado e independentemente de nossa capacidade cognitiva, por vezes também de qualquer conhecimento que the pudesse dizer respeito, humano ou outro. (PORCHAT PEREIRA, 1995, p. 9)

Em outros termos, o realismo metafísico pressupunha aquela natureza nítida em seus mínimos detalhes, até mesmo nas suas distâncias, cujo desvelar não se dava pela sua percepção ou cognição subjetiva, pois era parte de seu movimento o que dela se podia perceber ou conhecer. A verdade estava lá fora, como as qualidades primárias inerente às coisas em si mesmas, estava lá fora, além da janela de Alberti, para a qual a perspectiva convidava o olhar. Locke seria, assim, um materialista ainda ingênuo, um empirista a meio caminho entre a ciência moderna e a tradição metafísica. A noção vaga de uma substância dotada de qualidades em si mesma, "embora desconhecida", um último elo entre o conhecedor e a natureza. Elo problemático, já que estas são noções de Escola, tais como gênero e espécie. É evidente que a suspeita humeana da causalidade e a distinção kantiana entre fenômeno e coisa em si rompem definitivamente com tal laço; mas, quando se

\footnotetext{
${ }^{8}$ Locke recorre à figura de um indiano, ao qual se perguntou o que sustentava o mundo: "estava sustentado por um elefante, foi perguntado em que o elefante se apoiava, e respondeu: em uma grande tartaruga: sendo, porém, solicitado a desvendar em que se sustentava as costas largas da tartaruga, respondeu que era algo, mas não sabia o que".LOCKE, cap. XXIII, Livro III (19..., p. 206). Vale lembrar também que ora a "solidez" inere como qualidade à matéria, ora é apreendida por sensação.

${ }^{9}$ Há que se suspender a palavra entre aspas, já que ceticismo para Locke é, à maneira da parábola dos três servos, um erro: não devemos, por ter aparentemente recebido pouco, nada devolver ao criador em empenho, devemos multiplicar as possibilidades de conhecimento conforme o que nos foi dado, que é suficiente para todas as coisas humanas.

${ }^{10} \mathrm{Ou}$ seja, como pensa Michaud, a perspectiva não é antes de tudo ontológica, ou física, como para um cientista como Boyle, mas filosófica, epistemológica. MICHAUD, Locke, Rio de Janeiro: Zahar, 1991.
} 
tira as conseqüências lógicas da noção de ideia em Locke, prenuncia-se um primeiro corte.

O que Hume recusa em Locke - o uso ainda escolástico da noção dúbia de "ideia"11 - não teria sido uma sutil "descoberta" indireta, já que distante dos propósitos enunciados pelo autor, da fratura entre subjetividade e objetividade, apenas aprofundada pelo empirismo subsequente? $E$, neste questionamento aberto e em movimento, seu livro prenunciaria não só criticismo de Kant, mas também, como sugere Baxandall, uma outra noção de visualidade, cada vez mais restrita às capacidades ópticas e às sínteses subjetivas. Não se quer evidentemente pegar o autor no contrapé, recorrendo a uma psicologia ou a uma história contingente e factual, mas o contrário disso: a estratégia é pôr em foco o próprio tecido do texto, do qual a sua historicidade intrínseca e necessária emerge. Os antagonismos tensos da própria estrutura histórica do problema reaparecem, na obra, como descompassos formais internos ao texto, e as tais contradições são antes a própria exposição paralisada do movimento de cisão em curso. A natureza para Locke, como para De Piles, ainda pode ser una - ou no caso do empirista, "corpuscular" -, mas sua unidade, ontológica ou material, de alguma forma, depende de um claro-escuro cujo foco, a atenção, posicionam o sujeito e, por fim, são por ele posicionados. E é no cerne dessa aparente contradição, nesse jogo de luz e sombra, que o olho físico ou o "olho da alma", põem em cena aquelas "ideias escondidas" em camadas quase "subconscientes":

embora [estas ideias] por muitas vezes surjam também em nossas mentes de livre e espontânea vontade, e se revelem ao nosso entendimento, sendo outras despertadas e lançadas de suas celas escuras à luz do dia por paixões turbulentas e tempestuosas, fazendo com que nossos afetos tragam idéias para nossa memória, sem o que permaneceriam silenciosas e olvidadas (LOCKE, 1988, p. 46 )

Objetar-se-á tratar-se, no trecho acima, da operação da memória e não de uma operação geral do pensamento. Mas tal operação, reflexiva, sob o olho da alma como escreve o próprio Locke, em sua especificidade pode mostrar uma relação do pensamento a si mesmo, que escaparia à atomização das percepções em Hume, àquele solipisismos subjetivo que, como veremos, será intensificado até às formas psíquicas individualizadas em patologias íntimas, herança positiva do empirismo radical reformulada na ciência do século XIX.

\footnotetext{
${ }^{11}$ David Hume, Investigação sobre o entendimento humano, "Das origens das ideias", p. 60, nota.

${ }^{12}$ Desconsiderando aqui o problema da incognocibildiade da substância material, que trataremos a seguir.

${ }^{13}$ Se Boyle, e por vezes Locke, incluem solidez entre as qualidades da matéria, muitas vezes ela aparece nos Ensaios como mera sensação. Cf. E. McCANN, op cit.

${ }^{14}$ Sem investir nessa senda, apenas para situar, Newton pressupõe um duplo movimento complementar,
}

\section{A natureza da percepção}

A relação entre o mundo e a sua percepção é tema central dos Ensaios acerca do entendimento humano de Locke; ou melhor seria já dizer a relação entre o sujeito que conhece e o mundo que se lhe dá a conhecer? Para o autor, "seja o que for" a substancialidade, ela não é mais a pedra de toque da verdade, de uma realidade em si mesma, pois chega-nos apenas como uma "ideia", ou uma vaga noção de materialidade que unifica os dados múltiplos, experienciados por meio de sentidos distintos. Em visada materialista, em alguns trechos Locke chega a afirmar que a noção de substância nada mais é que um produto da reflexão ${ }^{12}$, ou uma idéia complexa formada a partir da matéria bruta das sensações atomizadas dos objetos - cor, cheiro, resistência"13 - "acrescentando a ideia de substância as ideias simples de uma certa cor opaca e esbranquiçada, com certo peso, dureza, ductibilidade e fusibilidade, obtemos a ideia de chumbo" (LOCKE, 1988, p. 52).

O que é a coisa chumbo? É uma cor esbranquiçada, uma ductibilidade, um peso. A substância essencial que porta tais acidentes e os unifica não é nem lógica nem cronologicamente conhecida antes da experiência; há, antes de tudo, experiências sensíveis específicas, descontínuas, cada qual recebida por um órgão dos sentidos, apartadas em sensações que nos chegam do mundo. As sensações preenchem a "sala de recepção da mente", mas para tanto já são percebidas pelo sujeito para formar idéias simples de sensação, já são percepções. O dado bruto dos sentidos não faz sua entrada no quarto vazio da mente sem mediações, de forma meramente empírica, como 'impressão vívida', pois passa por um perceber, um iluminar subjetivo dessa sensação, até a elaboração de sua idéia. Contradições que evidentemente não passaram sem críticas do incipiente empirismo, de Hume a Berkeley. A unidade do que seria o chumbo só vem posteriormente, como atuação do mesmo sujeito que reúne as parte do que percebeu, as ideias de sensação, em uma única ideia. Claro que Locke não põe em questão a realidade das coisas, os sentidos "retiram dos objetos externos para a mente o que Ihes produziu estas percepções" (LOCKE, 1988, p. 27). E a matéria tem suas qualidades inerentes, atomísticas. Locke pensa em uma natureza mecânica e materialista à maneira do século XVII, está, apesar das sutis aproximações, distante do ser é ser percebido que Berkeley avançara em $1710^{14}$. Da mesma forma seria anacrônico ler nas entrelinhas do autor um sujeito como mediador das sínteses da percepção sensível. 
Locke não chega a fazer uma distinção clara entre os momentos da percepção, como pensamento e sensação, como faz Hume. Para Hume, impressões e ideias são momentos absolutamente distintos, as sensações (ou impressões) internas ou externas são vívidas, inatas, no sentido de que são percepções originais da natureza humana; todas as ideias são derivadas de impressões, são sensações enfraquecidas, que organizamos segundo princípios naturais de associação e conexão; em Locke, muitas vezes os termos se misturam, pois parece haver uma imediata percepção dos objetos externos captados pelos sentidos ou dos movimentos da alma refletidos; apenas no capítulo IX, do Livro II, Locke explicita: "nasce na sensação apenas quando a mente pode nos dar ideia do que é percepção. Não existe percepção quando quaisquer alterações ocorridas em nosso corpo não alcançam a mente". Em certo sentido, essa passagem da sensação à ideia é tênue, já que percepção é "pensamento em geral" e o "primeiro passo e grau na direção do conhecimento e a entrada de todos os seus materiais". Muito embora Locke escreva que 'percepção' é uma ideia de reflexão, qualquer sensação só nos é efetiva se já for percepção, mesmo aquela de dor, "o fogo pode queimar nossos corpos sem outro efeito do que faz uma acha de lenha", caso tal sentido não se produza como percepção na mente, ou seja, a "idéia de dor ou sentimento de calor"15. Uma sensação que não é percepção, não é sentida, seria apenas ação mecânica: um raio de luz na retina, uma chama de fogo sobre a pele. As partículas que, nessa física de contato, emanam do átomo aglomerado em corpúsculos movem os sentidos e o cérebro fornecendo à mente ideias de sensação que podem vir a explicitar aquelas qualidades intrínsecas à matéria.

No caso das idéias de reflexão, aquelas que têm por objeto a própria mente em sua ação, a noção de percepção fica mais destacada, pois a mente pode atuar de forma não reflexiva, sem que se tenha consciência refletida de que ela atua, como ocorre com as crianças. O próprio Ensaio sobre o entendimento humano se vale, segundo Locke, desse esforço de consciência refletida: "o entendimento, como o olho, que nos faz ver e perceber todas as coisas, não se observa a si mesmo; requer arte e esforço situá-lo a distância e fazê-lo seu próprio objeto" (LOCKE, 1988, p. 7). Não apenas ver e perceber, mas também refletir sobre a operação de ver. Apesar de separar ideias de sensação de ideias de reflexão, a noção mediadora de percepção põe a reflexão como procedimento central: "quando as crianças chegam ao mundo pela primeira vez, - escreve Locke logo no primeiro capítulo do Livro II, sobre as ideias - encontramse rodeadas por uma infinidade de coisas novas, que, por constante solicitação de seus sentidos, orientam a mente constantemente para elas, avançando para observar de novo, e se deliciando com a variedade cambiante de objetos".

Esse olhar primeiro, ingênuo e infante, é movido pela solicitação da atenção reflexiva, a mesma que o claro escuro procura disciplinar para os objetos centrais de uma pintura. E a pintura é um exemplo rápido de atenção no mesmo Livro II, capítulo I,

A pintura ou o relógio podem estar de tal modo
situados que diariamente surgem no caminho de um
homem; mesmo assim, ele terá uma ideia confusa de
todas as parte de que são feitos enquanto não se aplicar
com atenção e considerar cada uma delas
pormenorizadamente (LOCKE, 1988, p. 29)

Mesmo que a contrapelo, pois para Locke a alma só pode ser inquirida se estivermos plenamente conscientes de seus movimentos, nunca em sonhos ou durante o sono, a noção de atenção consciente, equilibrada sobre uma miríade de pequenas desatenções oscilantes, flutuantes, ganha força. É sobre essa atenção/desatenção que pretendo falar no quarto final deste texto, a partir do comentário crítico de Gottfried Wilhelm Leibniz ao texto de Locke, nos Novos ensaios sobre o entendimento humano, redigidos entre 1701 e 1704, e publicados pelo alemão postumamente em 1765.

\section{Percepção insensível}

A partir da crítica a Locke, Leibniz entende que a alma, a consciência, não pode ser pensada de forma atomizada, descontínua. Não se pode pensar que a consciência se dá imediatamente, sem movimentos anteriores, deslocada de forma repentina do repouso da desatenção para o foco da atenção, como se houvesse um vazio e uma série causal nova a cada nova percepção movida pela consciência. Uma alma intermitente, que só pensa a si mesma quando está plenamente consciente desse pensar, seria imaginar que séries perceptivas ou reflexivas movem-se a partir do nada. Nessa réplica, está implicada também uma crítica ao atomismo materialista estrito, que pensa o ponto último como necessariamente matéria, átomo. Para Leibniz, o atomismo assenta-se sobre a hipótese de uma

mecanicismo e matemática: “ [...] os antigos (como nos conta Pappus) deram muitíssima importância à mecânica ['mekhané', máquina] na investigação das coisas naturais, e os modernos, rejeitando as formas substanciais e as qualidades ocultas, empenharam-se por submeter os fenômenos da natureza às leis da matemática [...]". Por "formas substancias", Newton entende a explicação essencialista da natureza. Isaac NEWTON, Princípios de matemática da filosofia natural [1685]. In: Os Pensadores, São Paulo: Abril Cultural, 1979, p. 3.

${ }^{15}$ A oscilação de termos, sensação/sentido de um lado, percepção/ idéia de outro não é claramente tematizada pelo autor. 


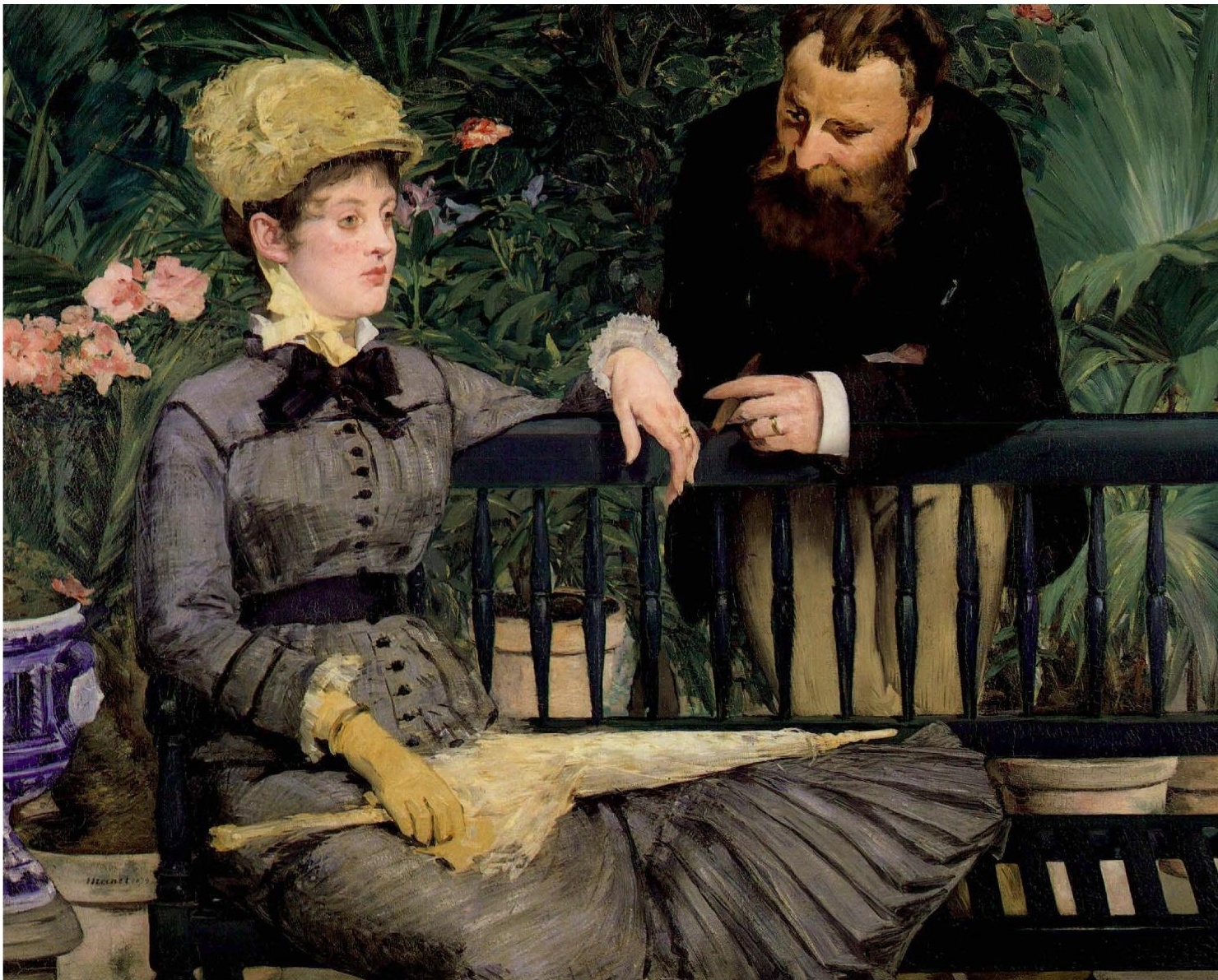

natureza descontínua, articulada por vazios que separam as partes da matéria, e o movimento resulta, assim, meramente mecânico e geométrico, uma troca de lugar no espaço vazio. Não se explica, por essa teoria, como há movimento contínuo e vir a ser na natureza, sem a necessária aparição, ex maquina, de uma força externa ao sistema para mover as partes inertes de um lugar ao outro. A resposta de Leibniz leva a uma natureza sem vazios, sem descontinuidades, na matéria como na alma. Uma matéria cujo "átomo" não é material, mas força, dinâmica - que depois na obra de Leibniz será entendido como o uno, a mônada. Se não há descontinuidade, não há saltos, toda atenção subjetiva deve equilibra-se sobre um múltiplo perceptivo anterior, movimento mínimo imperceptível, que, das bordas da desatenção carreia materiais ao centro aperceptivo consciente e forma-se, então, como algo de que se tem plena consciência. 0 exemplo mais contundente de Leibniz é uma imagem sensível, poder-se-ia dizer até mesmo contemplativa e, com o perdão do anacronismo, estética: nossa impressão geral, unificada em uma consciência, do som do mar. Nessa atenção final, apercebida como tal, move-se, entretanto, como as mínimas ondas do mar que confluem para a apreensão una do marulho, uma infinidade de séries perceptivas insensíveis, inconscientes, mas que dão à percepção final (apercepção) sua espessura tensa, contínua, múltipla. 0 termo de Leibniz para essa oscilação nas franjas da consciência é um oximoro barroco: percepção insensível. E cito o próprio autor:

toda atenção exige memória, e muitas vezes acontece, quando não cuidamos prestar atenção a alguma das nossas percepções presentes, que as deixemos passar sem reflexão e até sem notá-las: todavia, se alguém nos adverte imediatamente depois, e nos chama a atenção, por exemplo, para algum ruído que houve, lembramonos dele e nos damos conta de tê-lo percebido, de alguma forma. Por conseguinte, eram percepções das quais não nos tínhamos dado conta de imediato, sendo que a apercepção, neste caso, provém exclusivamente de havermos sido advertido depois de certo intervalo [...] Para ouvir o ruído [do mar] como se costuma fazer, é necessário que ouçamos as partes que compõem este todo, isto é, os ruídos de cada onda, embora cada um desses pequenos ruídos só se faça ouvir no conjunto confuso de todos os outros conjugados, isto é, no próprio bramir, que não se ouviria se esta onda que o produz estivesse sozinha (LEIBNIZ, 1984, p. 12) 
Sem levar muito longe a metáfora marinha de Leibniz, talvez ela não seja também tão estranha às imagens artísticas, cujo papel queremos entender. As oscilações cambiantes da percepção do mar podem ser vistas como uma tópica de pintura um tanto distante daquela concentrada nas academias, no geral orientadas pela disciplina do desenho, e então disseminadas por toda a Europa. Não é no centro do debate artístico do século XVIII que se encontram as marinhas, mas em suas bordas, desde as pinturas inglesas de aquarelistas, ou mesmo de William Turner, até o colorismo impressionista. Como uma linha subterrânea, a tensão dessa pintura menos legível e mais visível, que tomará o centro da cena talvez apenas com o Impressionismo, se vale de uma articulação de pinceladas dispersas, sem o arcabouço de um desenho organizador.

Voltando ao nosso início, à representação visual da atenção, autores como Jonathan Crary pensam a desatenção tão própria à forma de ver do mundo modernizado, a partir não só de dispositivos do ver, como a fotografia e o cinematógrafo, mas também da crescente subjetivação dos aspectos perceptivos da visão, cujo caminho passa pela questão da ótica e da sensibilidade; percepção cada vez mais enclausurada no sistema cognitivo do homem moderno e distante da percepção da natureza em si mesma. Daí o crescente interesse em dispositivos protéticos de visão: do caleidoscópio ao cinema, a natureza da percepção não é mais sua substância ou essência, mas seu simulacro científico, artificial. Os momentos, aliás, são dialeticamente encadeados em um nexo lógico material quando pensamos na ruptura epistêmica que faz da percepção visual um elo entre o biológico e o mecânico, com os estudos da óptica que vem a se cristalizar nos dispositivos visuais mecanizados do XIX. Do ponto de vista da teoria do conhecimento, Crary aponta a crescente subjetivação, ou mesmo individualização, que envia a questão dos níveis de atenção a um plano psíquico, para o qual a desagregação da percepção atomizada empirista não é mais epistemológica, mas individual.

Foi nessa época - fim dos anos 1870 e início de 1880 que uma sobreposição extraordinária de problemas tornou-se evidente, não só em algumas práticas do modernismo visual, mas também no estudo empírico da percepção e da cognição e no então novo estudo das patologias da linguagem e da percepção, em particular na França e na Alemanha. Se, por volta de 1880, certas áreas do modernismo e das ciência empíricas estavam explorando o campo perceptivo recém-decomposto em várias unidades abstratas de sensação e novas possibilidades de síntese, pesquisas contemporâneas sobre desordens nervosas recém-identificadas, como histeria, abulia, psicastenia e neurastenia descreviam várias fraquezas e insuficiências da integridade da percepção e seu colapso em fragmentos e insuficiências (CRARY, 2004, p. 77)
Trata-se não só do estudo empírico da "experiência", mas de uma desagregação da mente em relação a um real cada vez mais fantasmagórico, mediado por infinitos sistemas e dispositivos. Em um regime de trocas abstratas, tal como aquele do século XIX, a desatenção/atenção são capturadas por discursos ora científicos e mecânicos, ora patológicos. As ciências positivas do comportamento tomam o lugar da avaliação epistemológica do ato de perceber ou formar ideias, do mesmo modo que os mecanismos de ver tomam a cena da representação visual.

Com esse panorama positivista ao fundo, Jonathan Crary lê na imagem da mulher e do homem na tela $A$ estufa de Eduard Manet, de 1879, uma cifra dialética da nova noção de percepção moderna. O autor enfatiza a escolha de $A$ estufa por ser uma pintura na qual há uma espécie de recuo da liberdade das pinceladas manetiana, em prol de um desenho mais contido. Há uma tensão entre indiferença e atenção concentrada, quase hipnótica, entre uma natureza orgânica (as flores) e uma inorganicidade mecânica no corpo feminino que toma forma pelo vestido. Há, ainda, uma desarticulação da própria conversação que não se institui pelos olhares dispersos, vagamundos, nem pelos gestos mecanicizados, com algo de um automatismo fixo, de manequins. Os dedos do casal se encontram no centro da cena, mas de maneira dissimulada, recuada, clandestina. O fundo, de bruxuleante horror vacui, apesar da contenção das pinceladas, captura e recaptura o olhar, que se move do plano frontal ao recuado, em uma confusão óptica que funciona como artificio de atenção e, pelo excesso, de dispersão, tal como na cidade das trocas e do consumo. Uma atenção fluida e dinâmica pressuposta pelos novos meios de atração visual, que se move entre uma "realidade" cognoscível já muito subjetivada, sempre em vias de se fragmentar em fluxos ou fantasmagorias abstratas. Entre a desatenção visual de Chardin e a desatenção concentrada, no limite da dispersão, de Manet, um corte: o fim do laço metafísico que ainda articula as pequenas percepções ao todo em Leibniz, e o início de um mundo de trocas abstratas, atomizadas, subjetivadas até a patologia. Aqui, as pequenas percepções não se unem senão por um elo artificiosos: o contorno firme do desenho que o próprio Manet já havia tornado elástico, dúctil em outras telas. Mas, desse fundo desarticulado, ainda é Leibniz que podemos chamar para pensar a espessura desarmônica da imagem de Manet como cifra imanente da sua história, na qual:

as pequenas percepções, devido às suas consequências, são por conseguinte mais eficazes do que se pensa. São elas que formam este não sei o que, esses gostos, essas imagens das qualidades dos sentidos, claras no conjunto, porém confusas nas suas partes individuais, essas 
impressões que os corpos circunstantes produzem em nós, que envolvem o infinito, esta ligação que cada ser possui com todo o resto do universo (LEIBNIZ, 1984, p. 12)

Em Leibniz, cada um dos mínimos movimentos da matéria, seus pontos metafísicos indivisíveis, são pontos de vista que contém, como fundo inapercebido, percepções insensíveis, o todo. Cada mônada, cada unidade sem partes da matéria, fechada em si mesma, é um espelho do universo, apesar de apenas uma pequena parte deste vir à tona como 'consciência' - ou apercepção. Se Jonathan Crary, em seu ensaio sobre a desatenção, pensa nessa desagregação como de ordem psíquica, uma visada leibniziana devolve à imagem sua imanência e espessura temporal própria. Se não há mais uma harmonia externa a dar completude ao todo das percepções cada vez mais subjetivadas, a própria imagem sustém, na sua tensão interna formal, essa fratura entre atenção e desatenção, entre percepção e realidade.

Relacionei dois autores contemporâneos que tratam, cada um a seu modo, a percepção na imagem e seu limite, a desatenção. Em lugares diversos do espectro da interpretação histórica, ambos os autores, Baxandall e Crary, não esperam relação direta entre as pinturas e a teoria social ou epistemológica que lhes faz fundo. Ambos pensam em configurações que lhes são condições de possibilidade. Baxandall em visada que podemos dizer cognitivista, pois preocupada com as condições epistêmicas de cada época, e Crary, em uma relação sóciopolítica. Mesmo descontando a interpretação completa do sistema de Leibniz, articulado em suas partes pela metafísica da harmonia préestabelecida do mundo, a noção de percepção insensível permite-nos analisar, na espessura da própria imagem, suas camadas tensas, nas quais dorme um inconsciente histórico-social, a cuja historicidade até mesmo a sensibilidade empírica responde. Essa história da imagem não lhe é externa, e também não é parte de um inconsciente individual, ou coletivo à maneira a-histórica de um mito. Mas a história social the é imanente, seus interditos são objetivos, tecidos em suas instâncias mais próprias, mais específicas, mais formais - na própria configuração da imagem. Trata-se, essa inspeção 'monadológica', de uma espécie de devoção às ninharias insensíveis, internas ao próprio objeto, como escreve Walter Benjamin em carta a Adorno. Os limites meramente objetivos, formais, avaliados de modo coisal, ou 'filológico', desfolham o histórico implicado na imagem ou no texto. Para falar como Benjamin, o teor coisal da obra é que nos permite a abertura a sua verdade, sem necessariamente requerer uma mediação dialética externa, ou mesmo uma mediação pelo processo social. Nesse sentido, o modelo de exposição da percepção insensível me parece fundamental para a análise dos mecanismos objetivos de atenção.

\section{Referências bibliográficas}

ALBERTI, Leon Batista. Da Pintura. Campinas: Editora da Unicamp, 1992.

BAXANDALL, Michael."Os quadros e as ideia: Uma dama tomando chá de Chardin" in Padrões de intenção. A explicação histórica dos quadros. São Paulo: Companhia das Letras, 2006.

BENJAMIN, Walter. "As afinidades eletivas de Goethe" in Ensaios reunidos: Escritos sobre Goethe. São Paulo: Duas cidades, 34, 2009.

CRARY, Jonathan. "A visão que se desprende: Manet e o observador atento do fim do século XIX" in CHARNEY, Leo; SCHWARTZ, Vanessa (orgs.) O cinema e a invenção da vida moderna. São Paulo: Cosac \& Naify, 2004.

DA VINCI, Leonardo. Tratado da pintura. Madrid: Editora Nacional, 1982.

CARREIRA, Eduardo (org). Escritos de Leonardo da Vinci sobre arte e pintura. Brasília: editora da UnB, 2000.

DE PILES, Roger. Cours de peinture par principes. Paris: Gallimard, 1989.

FOUCAULT, Michel. As Palavras e as coisas. São Paulo: Martins Fontes, 1987

LEIBNIZ, Gottfried Wilhelm. Novos Ensaios. São Paulo: Abril Cultural, 1984. Col. Os Pensadores

LOCKE, John. Ensaio acerca do entendimento humano. São Paulo: Abril Cultural, 1988. Col. Os Pensadores.

McCANN, Erwin. "Lockean Mechanism" in Locke, ed. V. Chappell Oxford: Oxford University Press, 1998.

MICHAUD. Locke. Rio de Janeiro: Zahar, 1991.

PEREIRA, Oswaldo Porchat. "Verdade, realismo, ceticismo" in Discurso (25), 1995, 7-67.

ZATERKA, Luciana. “Robert Boyle e John Locke: hipótese corpuscular e filosofia experimental" in Circumscribere, 1 (2006), pp. 58-66. 
